\title{
Solar and Stellar Flares
}

edited by

BERNHARD M. HAISCH AND MARCELLO RODONÒ

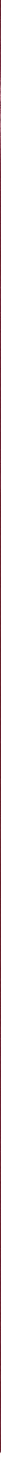

Kluwer Academic Publishers 
SOLAR AND STELLAR FLARES

https://doi.org/10.1017/S0252921100031730 Published online by Cambridge University Press 


\title{
SOLAR AND STELLAR FLARES
}

\author{
Proceedings of the 104th Colloquium \\ of the International Astronomical Union \\ held in Stanford, California, August 15-19, 1988
}

Edited by

BERNHARD M. HAISCH

Lockheed Palo Alto Research Laboratory, Palo Alto, California, U.S.A.

and

\section{MARCELLO RODONÒ}

Institute of Astronomy, University of Catania and Astrophysical Observatory, Catania, Italy

Reprinted from Solar Physics, Volume 121, Nos 1-2, 1989 


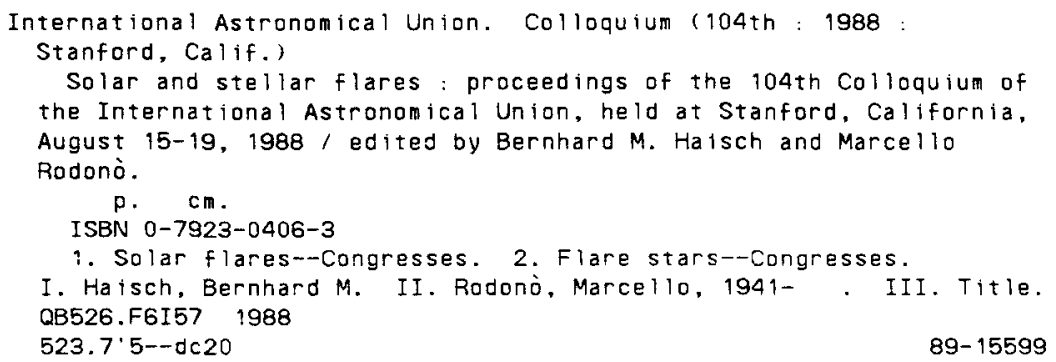

Published by Kluwer Academic Publishers, P.O. Box 17, 3300 AA Dordrecht, The Netherlands.

Kluwer Academic Publishers incorporates the publishing programmes of D. Reidel, Martinus Nijhoff, Dr W. Junk and MTP Press.

Sold and distributed in the U.S.A. and Canada by Kluwer Academic Publishers,

101 Philip Drive, Norwell, MA 02061, U.S.A.

In all other countries, sold and distributed by Kluwer Academic Publishers Group, P.O. Box 322, 3300 AH Dordrecht, The Netherlands.

Printed on acid free paper

All Rights Reserved

(c) 1989 by Kluwer Academic Publishers

No part of the material protected by this copyright notice may be reproduced or utilized in any form or by any means, electronic or mechanical, including photocopying, recording or by any information storage and retrieval system, without written permission from the copyright owner.

Printed in Belgium 
Dedicated to:

The Solar Maximum Mission Project

and

The Flare Star Consortium 


\section{TABLE OF CONTENTS}

(Solar and Stellar Flares)

EDITORIAL

PREFACE

Bernhard M. Haisch / An Overview of Solar and Stellar Flare Research

J. Aboudarham and J. C. Henoux / Electron Beam as Origin of White-Light Solar Flares

Ester AntonucCI / Solar Flare Diagnostic: Present and Future

P. B. BYRNE / Multi-Wavelength Observations of Stellar Flares

Brian R. DENNIS and Richard A. SCHWARTZ / Solar Flares: the Impulsive Phase

Wolfgang Dröge, Peter Meyer, Paul Evenson, and Dan Moses / Electron Acceleration in Solar Flares

A. Gordon Emslie / Models of Flaring Loops

Bernard H. Foing / Stellar Flare Spectral Diagnotics: Present and Future

M. R. Kundu, S. M. White, and E. J. Schmahl / Simultaneous MultiFrequency Imaging Observations of Solar Microwave Bursts

JEFFREY L. LINSKY / Solar and Stellar Magnetic Fields and Structures: Observations

Silvia H. B. Livi, Sara Martin, Haimin Wang, and Guoxiang Ai / The Association of Flares to Cancelling Magnetic Features on the Sun

Sara F. Martin / Mass Motions Associated with Solar Flares

D. J. MullaN / Solar and Stellar Flares: Questions and Problems

Donald F. NEIDIG / The Importance of Solar White-Light Flares

E. N. PARKER / Solar and Stellar Magnetic Fields and Atmospheric Structures: Theory

Giovanni Peres / Hydrodynamic Models of Solar and Stellar Flares

B. R. Pettersen / A Review of Stellar Flares and Their Characteristics 
J. H. M. M. SchmitT, J. R. Lemen, and D. ZARro / A Solar Flare Observed with the SMM and Einstein Satellites

N. I. Shakhovskaya / Stellar Flare Statistics - Physical Consequences 375

Peter A. Sturrock / The Role of Eruption in Solar Flares 387

ZDENĚK ŠvestKA / Solar Flares: The Gradual Phase

I. Tuominen, J. Huovelin, Yu. S. Efimov, N. M. Shakhovskoy, and A. G. ShCHerbakov / Polarimetry of Stellar Active Regions and Flares

Loukas Vlahos / Particle Acceleration in Solar Flares

V. V. ZheleznYAKov and E. YA. ZlotNiK / Cyclotron Lines in the Spectra of Solar Flares and Solar Active Regions

Discussions

INDEX 